\title{
Aromatic Aldehydes and Carboxylic Acids as inhibitors for Sickle Hemoglobin Polymerization
}

\author{
Ahmed S Mehanna* and Omeima Abdullah \\ Department of Pharmaceutical Sciences, MCPHS University, USA
}

Received: December 06, 2017; Published: March 27, 2018

*Corresponding author: Ahmed S Mehanna, Department of Pharmaceutical Sciences, MCPHS University, School of Pharmacy, Boston, USA,

Tel: 617.732.2955; Email: ahmed.mehanna@mcphs.edu

Abstract

The reported inhibitory effects of the natural products vanillin and 5-hydroxymethylfurfural prompted us to assess the anti-polymerization activities of several structurally related aromatic aldehydes and carboxylic acids. In addition to vanillin and 5-hydroxymethylfurfural, eleven more structurally related aromatic aldehydes and carboxylic acids including 2,4-dihydroxy benzaldehyde, furfural, 3-furfural, 5-methylfurfural, vanillic acid, 2-hydroxy-3-methoxy-benzoic acid, homovanillic acid, mandelic acid, 4-hydroxy-3-methoxy-mandelic acid, 4-bromo-mandelic acid and4-trifluromethyl-mandemic acid are evaluated for activity using our newly reported high throughput kinetic assay designed to study sickle cell hemoglobin polymerization kinetics. Several of the tested compounds exhibited promising anti-polymerization activities, comparable to that of vanillin and 5-hydroxymethylfurfural, includinghomovanillic acid, mandelic acid, 3-hydroxy-3-methoxymandelic acid, and 3-furfural. The structure activity relationship of all tested compounds is included.

Keywords: Sickle Cell Anemia; Sickle Hemoglobin; Homovanillic Acid; Mandelic Acid; Vanillin, Furfural

Abbreviations: SCA: Sickle cell anemia; HbA: Hemoglobin Molecule; HbS: Sickle Hemoglobin;

\section{Introduction}

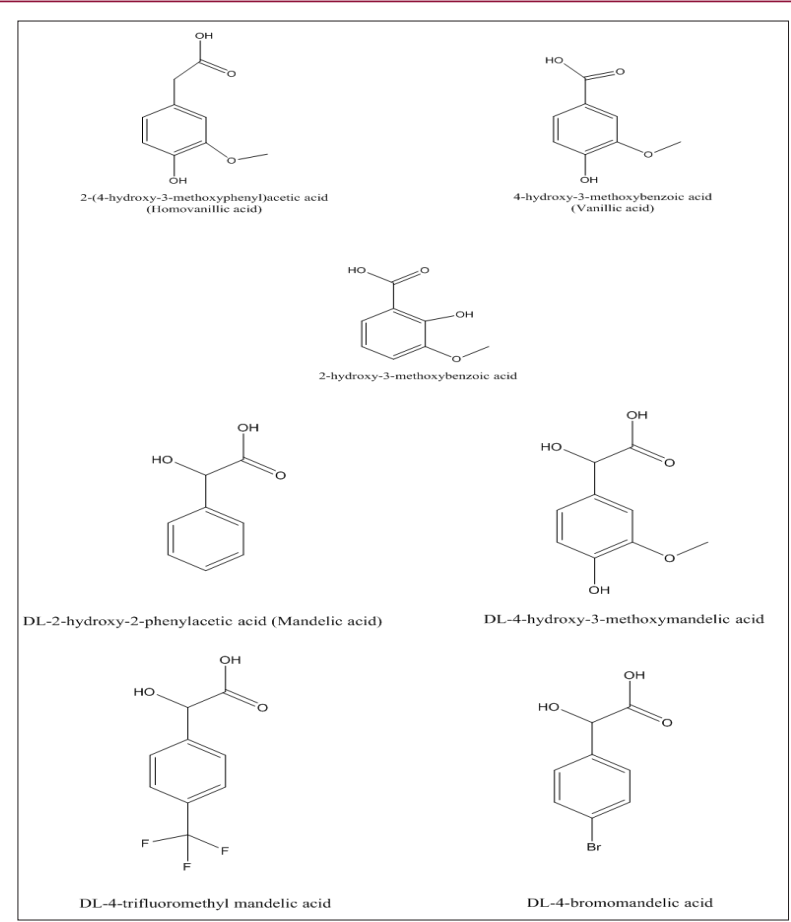

Figure 1: Vanillin and related aldehydes \& carboxylic acids. 
Sickle cell anemia (SCA) is a hematological disease caused by a single point mutation of Glu to Val at the $6^{\text {th }}$ position of the $\beta$-chain of the normal hemoglobin molecule $(\mathrm{HbA})$. The mutant hemoglobin, referred to as Sickle Hemoglobin (HbS), polymerizes inside the red blood cells under deoxygenated conditions leading to its distortion into the sickle shape, hence the name sickle cell anemia, leading to severe vaso-occlusion crises; which in many cases are fatal [1]. One of the approaches to develop therapeutic agents to treat the disease is to inhibit the polymerization process or delay its onset to allow deoxygenated blood to pass to the lung. In search of such agents that can inhibit or delay the polymerization, we have developed recently a high throughput assay screen organic compounds and natural products for anti-polymerization activities [2]. The assay helped in the identification of several thiol-containing compounds as potential anti-polymerization agents [3]. The thiol paper prompted us to apply the assay for screening several aromatic aldehydes and the corresponding carboxylic acids for activity. The selection of the aldehyde compounds was triggered by our earlier reports that vanillin [4] Figure 1. And 5-hydroxymethylfurfural (5HMF), [5,6] Figure 2. Both processed promising activities. In search of, more active compounds, the current study reports the result of screening several vanillin and furfural like compounds, some of which are naturally occurring materials; signifying potential safe properties. (Figures $1 \& 2$ ) depict the structures of the selected structurally related aromatic aldehydes and carboxylic acids.



Figure 2: Furfural and structural related aldehydes.

\section{Results and Discussion}

\section{Vanillin and Related Aldehydes}

4-Hydroxy-3-Methoxybenzaldehyde (Vanillin) (Structure 1)

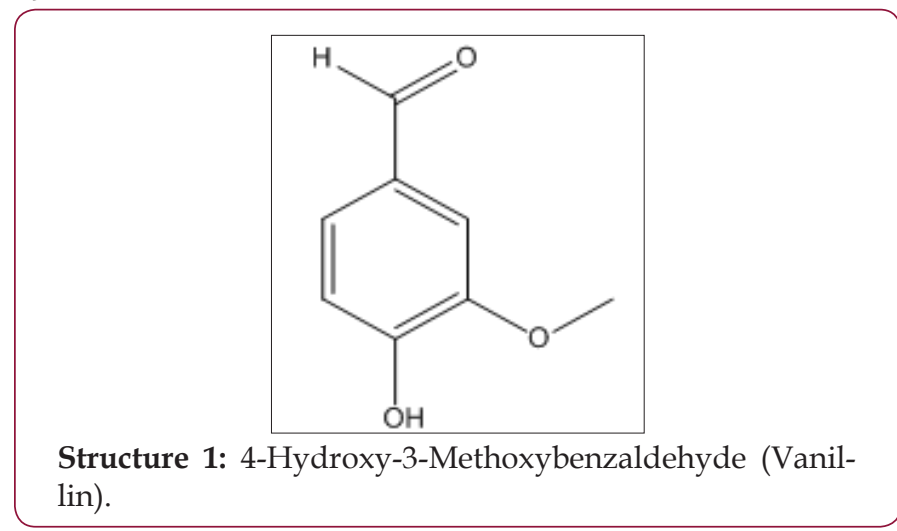

Vanillin showed a concentration-dependent anti-polymerization activity at a concentration range of $2-50 \mathrm{mM}$, with delay times represented by the Td50 values ranging from 3-8 minutes as shown in Figure 3 and Table 1. The latter, also depicts the number of folds in delaying the polymerization process relative to the control values to range from 1.2 to 2.9 folds. It is worthy to indicate that that we previously reported the anti-polymerization activity of vanillin, but with a different costly assay system [4]. Delay times are represented as mean $\pm \mathrm{SD}, \mathrm{n}=4 .{ }^{* *}$, *Statistically different from control at $p<0.001$ and $p<0.014$, respectively. Fold values calculated by dividing the delay times $\mathrm{Td}_{50}$ by $\mathrm{Tc}_{50}$.

Table 1: $\mathrm{Td}_{50}$ values for vanillin concentrations and folds relative to $\mathrm{Tc}_{50}$.

\begin{tabular}{|c|c|c|}
\hline Control & $\mathrm{Tc}_{50}$ (minutes) & \multirow{3}{*}{ Folds } \\
\hline Contro & $2.7 \pm 0.6$ & \\
\hline Concentration (mM) & $\mathrm{Td}_{50}$ (minutes) & \\
\hline 5 & $3 \pm 0.4$ & 1.2 \\
\hline 10 & $3 \pm 0.8$ & 1.2 \\
\hline 15 & $4 \pm 1.0$ & 1.4 \\
\hline 25 & $6^{*} \pm 0.8$ & 2.2 \\
\hline 50 & $8^{* *} \pm 1.3$ & 2.9 \\
\hline
\end{tabular}

\section{2,4-Dihydroxybenzaldehyde (Structure 2)}

The compound close structural similarity to vanillin prompted us to test it. Unfortunately, the absence of the m-methoxy group of vanillin led to complete loss of activity at the highest soluble concentration of $7.5 \mathrm{mM}$ as depicted in Figure 3 Band Table 2, Figure 3 indicates that the compound, after 4 minutes, results in higher optical reading that could be explained, in part, that the adduct produced by the interaction of the compound with HbS may higher reading than the control at wave length 700 . Delay times are represented as the mean $\pm S D, n=4$. Fold values calculated by dividing the Td 50 values by Tc50.

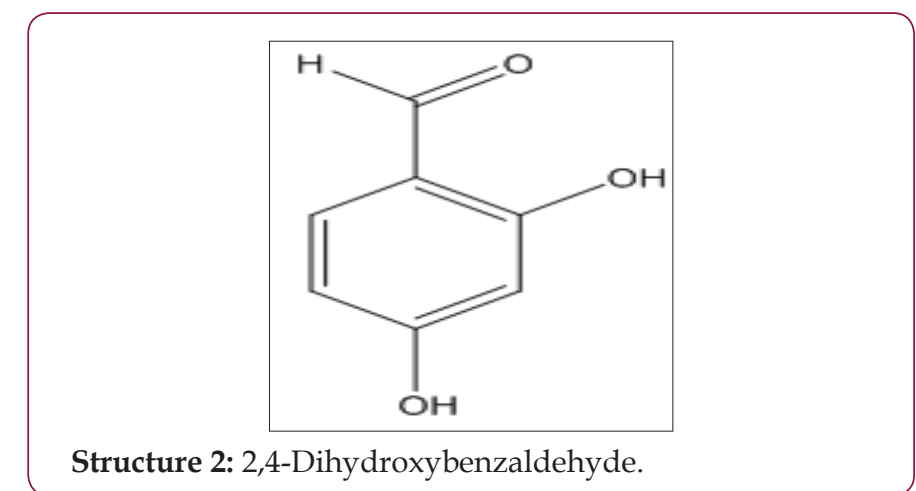

Table 2: $\operatorname{Td}_{50}$ values of 2, 4-dihydroxybenzaldehyde concentrations and folds relative to $\mathrm{Tc}_{50}$.

\begin{tabular}{|c|c|c|}
\hline \multirow{2}{*}{ Control } & $\mathbf{T c}_{\mathbf{5 0}}$ (minutes) & \multirow{2}{*}{ जolds } \\
\cline { 2 - 2 } & $\mathbf{2} \pm \mathbf{0 . 5}$ & \multirow{2}{*}{ Folds } \\
\hline Concentration (mM) & $\mathbf{T c}_{50}$ (minutes) & \\
\hline 7.5 & $2 \pm 0.1$ & 1 \\
\hline
\end{tabular}




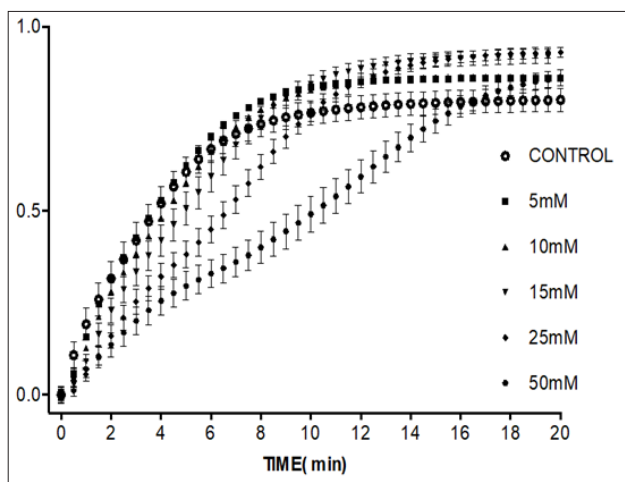

A

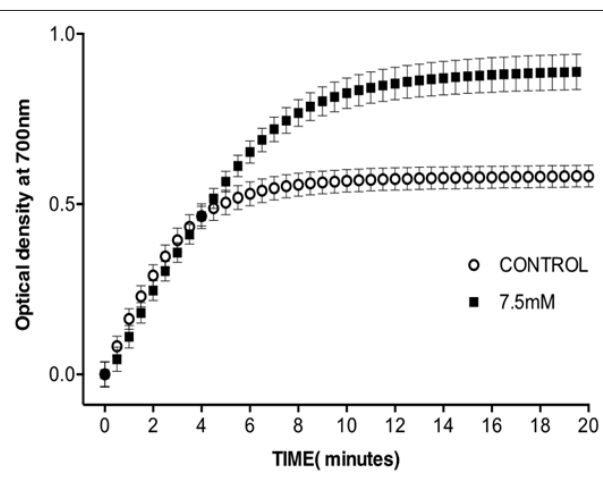

B

Figure 3: A. Effect of vanillin on $\mathrm{HbS}$ polymerization at concentrations 5, 10, 15, 15, 25 and 50mM. B. Effect of 2,4-dihydroxybenzaldehyde on HbS polymerization at 7.5mM.

\section{Vanillin-related Carboxylic acids}

4-Hydroxy-3-Methoxybenzoic Acid (Vanillic Acid) (Structure 3)

Vannilic acid and other carboxylic acid analogs of vanillin were evaluated to offset the poor solubility of vanillin and 2,4-dihydroxybenzaldehyde in the assay buffer. Unfortunately, vannilic acid exhibited noanti-polymerization activity even at high concentrations as $75 \mathrm{mMas}$ indicated in Figure 4 and Table 3. Delay times are represented as the average $\pm S D, n=4$. Fold values are calculated by dividing $\mathrm{Td}_{50}$ by $\mathrm{Tc}_{50}$.

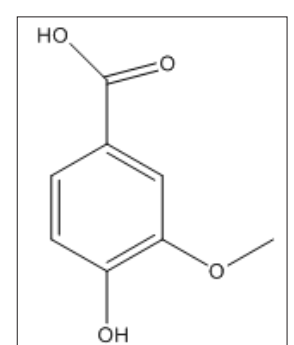

Structure 3: 4-Hydroxy-3-Methoxybenzoic Acid (Vanillic Acid).
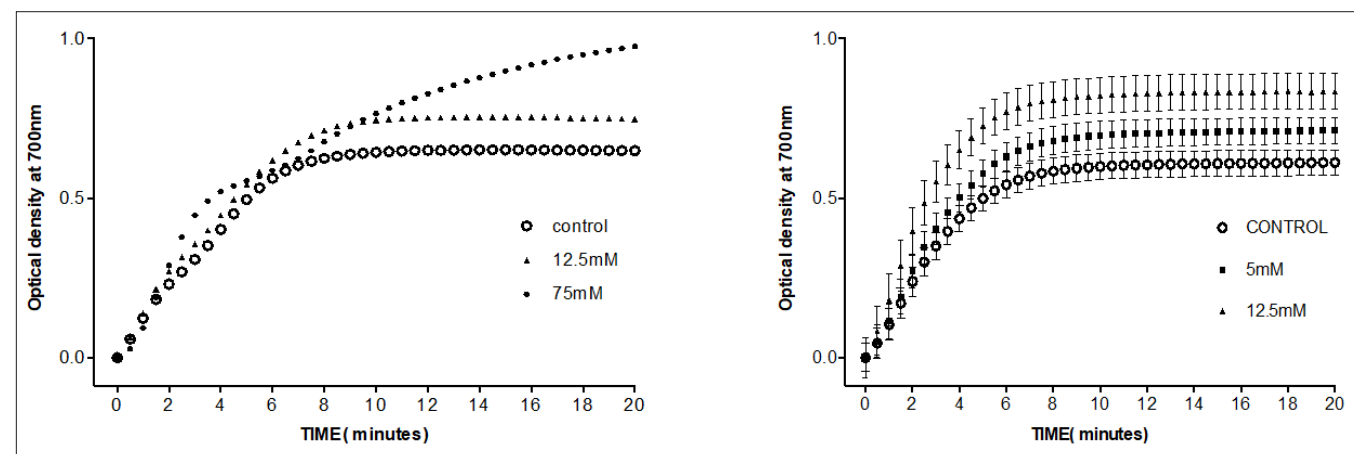

A

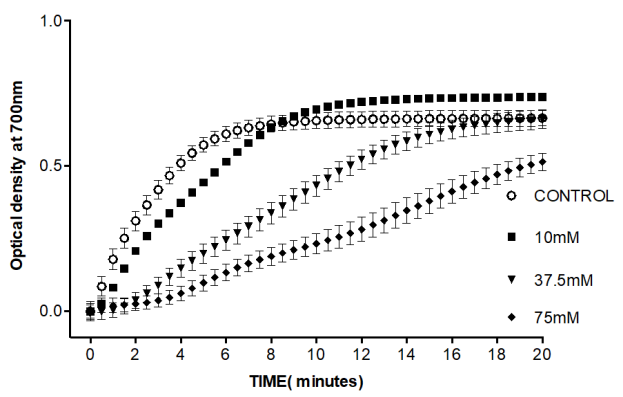

C

Figure 4: A. Effect of vanillic acid on HbS polymerization at concentrations of 12.5 and $75 \mathrm{mM}$. B. Effect of 2-hydroxy-3methoxybenzoic acid on HbS polymerization at concentrations of 5 and $12.5 \mathrm{mM}$. C. Effect of homovanillic acid on HbS polymerization at concentrations of $10,37.5$ and $75 \mathrm{mM}$. 
Table 3: $\mathrm{Td}_{50}$ values of vanillic acid concentrations and folds relative to $\mathrm{Tc}_{50}$.

\begin{tabular}{|c|c|c|}
\hline \multirow{2}{*}{ Control } & $\mathbf{T c}_{\mathbf{5 0}}$ (minutes) & \multirow{2}{*}{} \\
\cline { 2 - 2 } & $\mathbf{3} \mathbf{*}$ Fo.7 & \multirow{2}{*}{ Folds } \\
\hline Concentration $(\mathbf{m M})$ & $\mathbf{T d}_{\mathbf{5 0}}$ (minutes) & \\
\hline 12.5 & $2 \pm 0.7$ & 0.7 \\
\hline 75 & $2 \pm 0.2$ & 0.7 \\
\hline
\end{tabular}

\section{2-Hydroxy-3-Methoxybenzoic Acid (Structure 4)}

The compound is an isomer of vanillic acid with the hydroxyl group moved to the o-position. Unfortunately, as the case with vanillic acid, the compound demonstrated noanti-polymerization activity; even at the highest soluble concentration of 12.5 mMas shown in Table 4 and Figure 4. Delay times are represented as the average $\pm S D, n=4$. Fold values, calculated by dividing all $\mathrm{Td}_{50}$ by $\mathrm{Tc}_{50}$.

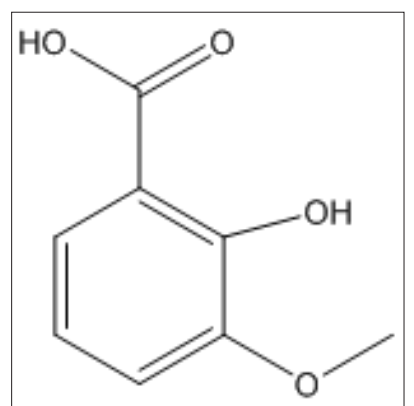

Structure 4: 2-Hydroxy-3-Methoxybenzoic Acid.

Table 4: $\mathrm{Td}_{50}$ values of 2-hydroxy-3-methoxybenzoic acid concentrations and folds relative to $\mathrm{Tc}_{50}$.

\begin{tabular}{|c|c|c|}
\hline \multirow{2}{*}{ Control } & $\mathbf{T c}_{\mathbf{5 0}}$ (minutes) & \multirow{2}{*}{ Folds } \\
\cline { 2 - 2 } & $\mathbf{3} \pm \mathbf{1 . 7}$ & \multirow{2}{*}{ Folds } \\
\hline Concentration $\mathbf{( m M )}$ & $\mathbf{T d}_{\mathbf{5 0}}$ (minutes) & \\
\hline 5 & $3 \pm 0.8$ & 1 \\
\hline 12.5 & $2 \pm 0.7$ & 0.7 \\
\hline
\end{tabular}

\section{4-Hydroxy-3-Methoxyphenylacetic Acid (Homovanillic acid) (Structure 5)}

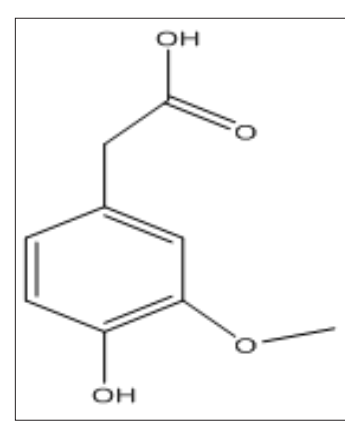

Structure 5: 4-Hydroxy-3-Methoxyphenylacetic Acid (Homovanillic acid).

The compound is a homolog of vanillic acid as derivative of phenyl acetic acid instead of benzoic acid. To our surprise, unlike vanilic acid, homovanillic acid exhibited a concentration dependent inhibition of $\mathrm{HbS}$ at concentrations of $10,37.5$ and $75 \mathrm{mM}$, with
Td50values of 3, 6 and 13 minutes, respectively, as shown in Figure 4 and Table 5. Delay times are represented as the average $\pm S D, n=4$. $*$, ** statistically different from Control at $\mathrm{p}<0.05$ and $p<0.001$, respectively. Fold values are calculated by dividing all $\mathrm{Td}_{50}$ by $\mathrm{Tc}_{50}$.

Table 5: $\mathrm{Td}_{50}$ values of homovanillic acid concentrations and folds relative to $\mathrm{Tc}_{50}$.

\begin{tabular}{|c|c|c|}
\hline \multirow{2}{*}{ Control } & $\mathbf{T c}_{\mathbf{5 0}}$ (minutes) & \multirow{2}{*}{\multicolumn{2}{|c|}{}} \\
\cline { 2 - 2 } & $\mathbf{1} \pm \mathbf{0 . 7}$ & \multirow{2}{*}{ Folds } \\
\hline Concentration (mM) & $\mathbf{T d}_{\mathbf{5 0}}$ (minutes) & \\
\hline 10 & $3 \pm 1$ & 3 \\
\hline 37.5 & $6^{*} \pm 2$ & 6 \\
\hline 75 & $13^{* *} \pm 5$ & 13 \\
\hline
\end{tabular}

\section{Mandelic Acid and Derivatives}

DL- 2-Hydroxy-2-Phenylacetic Acid (Mandelic Acid) (Structure 6)

Mandelic acid, $\alpha$-hydroxyl phenyl-acetic acid, exhibited considerable concentration-dependent delay in $\mathrm{HbS}$ polymerization, at concentration range of $10-100 \mathrm{mM}$.The compound delayed the polymerization process (Td50) for up to more than 20 minutes at $100 \mathrm{mM}$ concentration, as shown in Table 6 and Figure 5A. Delay times are represented as the average $\pm S D, n=4$. * Statistically different from control at $\mathrm{p}<0.001$. Fold values are calculated by dividing $\mathrm{Td}_{50}$ by $\mathrm{Tc}_{50}$.

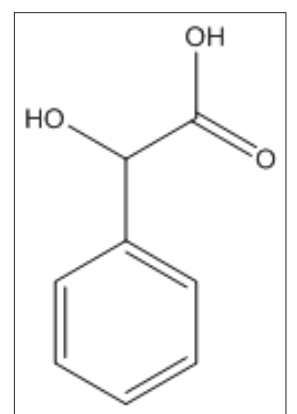

Structure 6: DL- 2-Hydroxy-2-Phenylacetic Acid (Mandelic Acid).

Table 6: $\mathrm{Td}_{50}$ values of DL-mandelic acid concentrations and folds relative to $\mathrm{Tc}_{50}$.

\begin{tabular}{|c|c|c|}
\hline \multirow{2}{*}{ Control } & $\mathbf{T c}_{\mathbf{5 0}}$ (minutes) & \multirow{2}{*}{ Folds } \\
\cline { 2 - 3 } & $\mathbf{3} \pm \mathbf{0 . 6}$ & \multirow{2}{*}{ Fold } \\
\hline Concentration (mM) & $\mathbf{T d}_{\mathbf{5 0}}$ (minutes) & \\
\hline 10 & $3 \pm 1$ & 1 \\
\hline 20 & $4 \pm 0.9$ & 1.3 \\
\hline 30 & $4 \pm 1$ & 1.3 \\
\hline 50 & $7^{*} \pm 2$ & 1.8 \\
\hline 100 & $>20$ & $>6$ \\
\hline
\end{tabular}



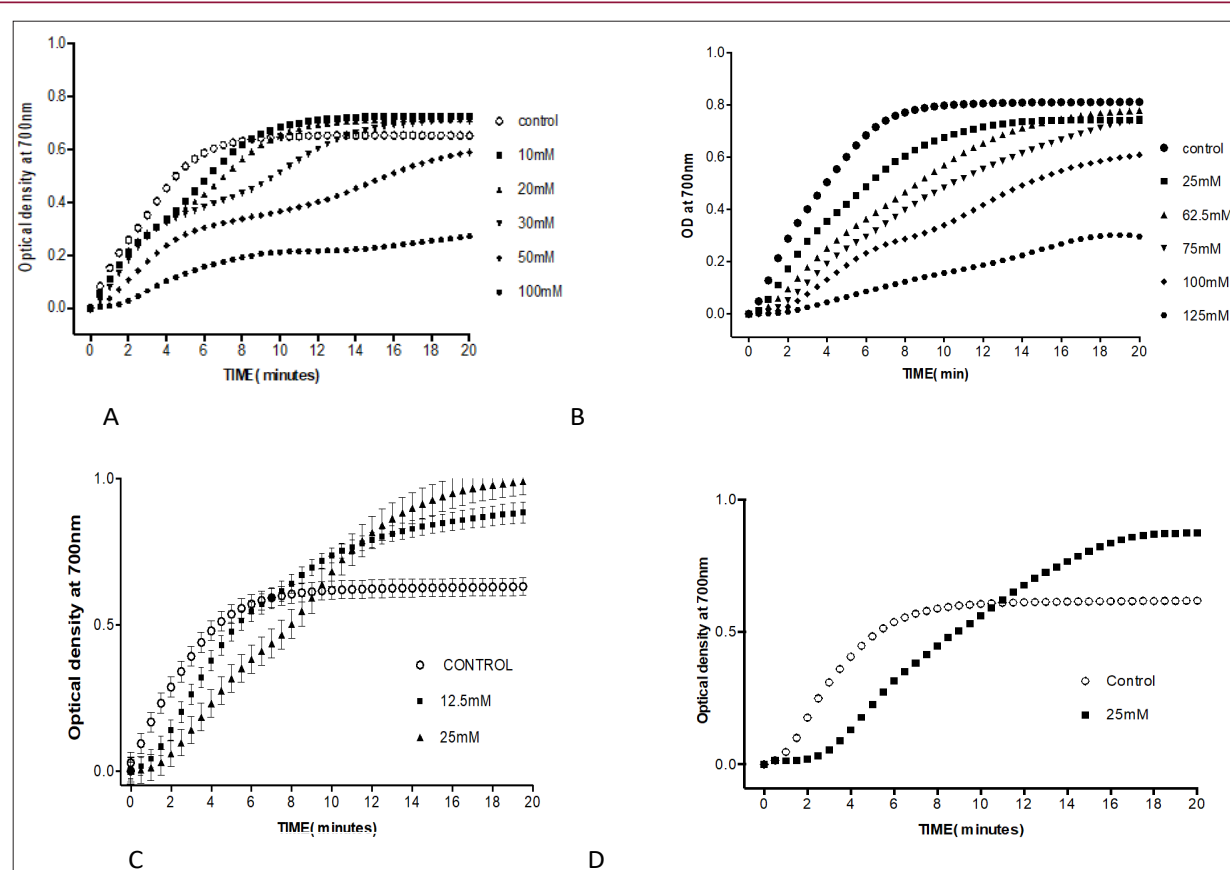

B

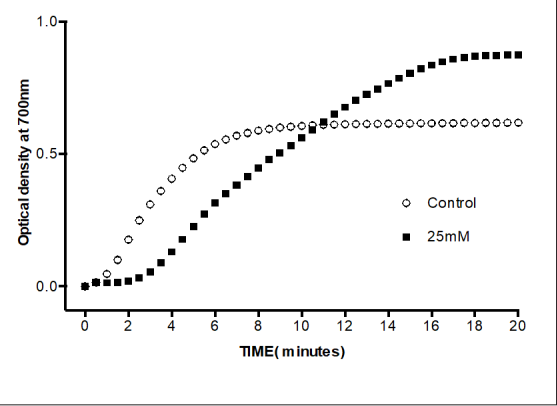

Figure 5: Effects of DL-mandelic acid and its derivatives on HbS polymerization A. DL-mandelic acid, B. DL- 4-hydroxy-3 methoxymandelic acid, C. DL-4-bromomandelic acid D. DL-4-trifluoromethylmandelic acid.

\section{Dl-4-Hydroxy-3-Methoxymandelic Acid (Structure 7)}

The compound, combines vanillin substitution on the benzene ring and the backbone of mandelic acid exhibited very similar activities to that of mandelic acid in a concentration dependent fashion as shown in Table 7 and Figure 5. This finding indicates that the mandelic acid backbone is more essential for activity than the vanillin substitution. Delay times are represented as the average $\pm \mathrm{SD}, \mathrm{n}=4$. $^{*}$ statistically different from the control at $\mathrm{p}<0.001$. Fold values calculated by dividing $\mathrm{Td}_{50}$ by $\mathrm{Tc}_{50}$.<smiles>O=C(O)C(O)c1ccc(O)c(OCCCCO)c1</smiles>

Structure 7: Dl-4-Hydroxy-3-Methoxymandelic Acid.

Table 7: $\mathrm{Td}_{50}$ values of DL- 4-hydroxy-3 methoxymandelic acid and folds relative to $\mathrm{Tc}_{50}$.

\begin{tabular}{|c|c|c|}
\hline Control & $\mathrm{Tc}_{50}$ (minutes) & \multirow{3}{*}{ Folds } \\
\hline Comtir of & $3 \pm 0.6$ & \\
\hline Concentration (mM) & $\mathrm{Td}_{50}$ (minutes) & \\
\hline 25 & $4 \pm 0.6$ & 1.3 \\
\hline 62.5 & $6 * \pm 0.6$ & 2 \\
\hline 75 & $7 * \pm 0.3$ & 2.3 \\
\hline 100 & $11^{*} \pm 1$ & 3.6 \\
\hline 125 & $>20$ & $>6$ \\
\hline
\end{tabular}

\section{DL-4-Bromomandelic Acid (Structure 8)}

The compound; was tested to investigate the effect of halogen substitution on the anti-polymerization activity of mandelic acid. Unfortunately, the bromo-substitution led to a considerable decrease in the anti-polymerization activity at the maximum solubility concentration of $25 \mathrm{mM}$ as depicted in Table 8 and Figure 5. Delay times are represented as the average $\pm S D, n=4$. * Statistically different than control at $p<0.001$. Fold values are calculated by dividing $\mathrm{Td}_{50}$ by $\mathrm{Tc}_{50}$.



Structure 8: DL-4-Bromomandelic Acid.

Table 8: $\mathrm{Td}_{50}$ values of DL-4-bromomandelic acid concentrations and folds relative to $\mathrm{Tc}_{50}$.

\begin{tabular}{|c|c|c|}
\hline \multirow{2}{*}{ Control } & $\mathbf{T c}_{\mathbf{5 0}}$ (minutes) & \multirow{2}{*}{ Folds } \\
\cline { 2 - 2 } & $\mathbf{3} \pm \mathbf{0 . 5 9}$ & \multirow{2}{*}{ Folds } \\
\hline Concentration (mM) & $\mathbf{T d}_{\mathbf{5 0}}$ (minutes) & \\
\hline 12.5 & $4 \pm 0.5$ & 1.3 \\
\hline 25 & $5^{*} \pm 1$ & 1.7 \\
\hline
\end{tabular}




\section{Dl-4-Trifluoromethyl-Mandelic Acid (Structure 9)}

Substituting mandelic acid with rifluromethyl group resulted in poor activity almost identical to that of the 4-bromo mandelic acid as depicted in Table 9 and Figure 5.

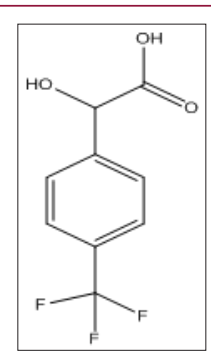

Structure 9: Dl-4-Trifluoromethyl-Mandelic Acid.

Table 9: $\operatorname{Td}_{50}$ values of 4-trifluoromethylmandelic acid concentrations relative to $\mathrm{Tc}_{50}$.

\begin{tabular}{|c|c|c|}
\hline \multirow{2}{*}{ Control } & $\mathbf{T c}_{50}$ (minutes) & \multirow{2}{*}{} \\
\cline { 2 - 2 } & $\mathbf{3} \pm \mathbf{0 . 4}$ & \multirow{2}{*}{ Folds } \\
\cline { 1 - 2 } Concentration (mM) & $\mathbf{T d}_{50}$ (minutes) & \multicolumn{2}{|c|}{} \\
\hline 25 & $5^{*} \pm 0.5$ & 1.7 \\
\hline
\end{tabular}

\section{5-Hydroxymethyl-2-Furfural (5-HMF) (Structure 10)}

The compound, a naturally occurring aromatic aldehyde. Earlier studies revealed that 5-HMF forms a high-affinity Schiffbase adduct with $\mathrm{N}$-terminal of $\alpha$-Val 1 of $\mathrm{HbS}$ and inhibits the suckling process through covalent binding [7]. Accordingly, 5-HMF was considered for evaluation under our new screening assay. The compound has demonstrated a substantial anti-polymerization activity in concentration-dependent manner at concentrations of 50, 75, 100, 125 and 150mM with Td50 of 4, 5, 8, 11 and 16 mins, respectively, as depicted in Table 10 and Figure 6. Delay times are

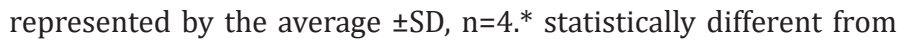
control at $p<0.001$. Fold values are calculated by dividing $\operatorname{Td}_{50}$ by $\mathrm{Tc}_{50}$.

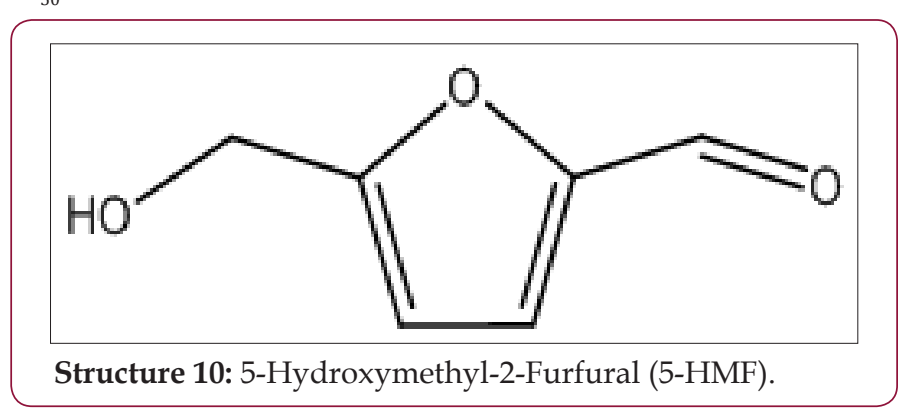



Figure 6: Effect of 5-HMF and its derivatives on HbS polymerization. A. 5-HMF, B. FUF, C. 3-FUF, D. 5-MF.

Table 10: $\mathrm{Td}_{50}$ values of 5-HMF concentrations and folds relative to $\mathrm{Tc}_{50}$.

\begin{tabular}{|c|c|c|}
\hline \multirow{2}{*}{ Control } & $\mathbf{T c}_{\mathbf{5 0}}$ (minutes) & \multirow{2}{*}{ Fold } \\
\cline { 2 - 2 } & $\mathbf{3} \pm \mathbf{0 . 2}$ & \\
\hline 5-HMF concentrations $\mathbf{( m M )}$ & $\mathbf{T d}_{\mathbf{5 0}}$ (minutes) & \\
\hline 50 & $4 \pm 0.8$ & 1.3 \\
\hline 75 & $5^{*} \pm 1.5$ & 1.7 \\
\hline 100 & $8^{*} \pm 3$ & 2.7 \\
\hline
\end{tabular}

\begin{tabular}{|l|l|l|}
\hline 125 & $11^{*} \pm 3$ & 3.7 \\
\hline 150 & $16^{*} \pm 2$ & 5.3 \\
\hline
\end{tabular}

\section{Furfural (FUF) (Structure 11)}

Furfural demonstrated, in a concentration dependent manner, slight anti-polymerization activities at 10,37 and $75 \mathrm{mM}$ as shown in Table 11 and Figure 6. Delay times are represented by the average $\pm \mathrm{SD}, \mathrm{n}=4$.* statistically different from control at $\mathrm{P}<0.04$. Fold values were calculated by dividing all $\mathrm{Td}_{50}$ by $\mathrm{Tc}_{50}$. 


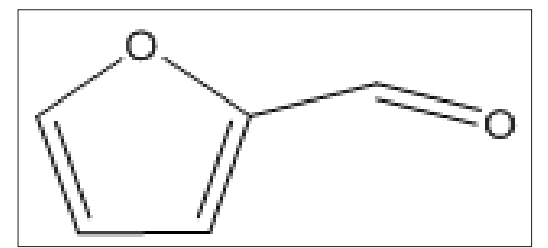

Structure 11: Furfural (FUF).

Table 11: $\mathrm{Td}_{50}$ values of furfural concentrations and folds relative to $\mathrm{Tc}_{50}$.

\begin{tabular}{|c|c|c|}
\hline \multirow{2}{*}{ Control } & $\mathbf{T c}_{\mathbf{5 0}}$ (minutes) & \multirow{2}{*}{ Fold } \\
\cline { 2 - 2 } & $\mathbf{2 \pm \mathbf { 0 . 1 }}$ & \\
\hline Furfural concentrations $\mathbf{( m M )}$ & $\mathbf{T d}_{\mathbf{5 0}}$ (minutes) & \\
\hline 10 & $2 \pm 0.3$ & 1 \\
\hline 37.5 & $3 \pm 0.8$ & 1.5 \\
\hline 75 & $4^{*} \pm 1$ & 2 \\
\hline
\end{tabular}

\section{3-furfural (3-FUF) (Structure 12)}

The compound has the position of aldehyde group in the 3 position instead of the 2 position of FUF. When compared to furfural; 3-FUF exhibited better anti-polymerization activities in a concentration-dependent range of $25-75 \mathrm{mM}$ as depicted in Table 12 and Figure 6 . Delay times are represented by the average $\pm S D$, $\mathrm{n}=4$. ${ }^{*}$ Statistically different from control at $p<0.001$. Fold values are calculated by dividing $\mathrm{Td}_{50}$ by $\mathrm{Tc}_{50}$.

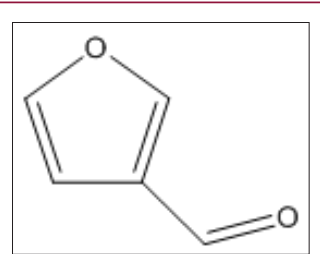

Structure 12: 3-furfural (3-FUF).

Table 12: $\mathrm{Td}_{50}$ values of 3-furfural concentrations and folds relative to $\mathrm{Tc}_{50}$.

\begin{tabular}{|c|c|c|}
\hline \multirow{2}{*}{ Control } & $\mathbf{T c}_{\mathbf{5 0}}$ (minutes) & \multirow{2}{*}{ Fold } \\
\cline { 2 - 2 } & $\mathbf{3} \pm \mathbf{0 . 4 5}$ & \\
\hline 3-furfural concentrations (mM) & $\mathbf{T d}_{\mathbf{5 0}}$ (minutes) & \\
\hline 25 & $6^{*} \pm 0.63$ & 2 \\
\hline 50 & $8^{*} \pm 0.57$ & 2.7 \\
\hline 75 & $9^{*} \pm 0.43$ & 3 \\
\hline
\end{tabular}

\section{5-Methylfurfural (5-Mf) (Structure 13)}

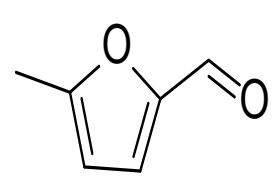

Structure 13: 5-Methylfurfural (5-Mf).

The compounds showed no significant delay in $\mathrm{HbS}$ polymerization relative to control as indicated in Table 13 and Figure 6. That indicates the importance of the hydroxyl group in

5 -HMF for activity. Delay times are represented by the average \pm SD, $\mathrm{n}=4$. Fold values were calculated by dividing $\mathrm{Td}_{50}$ by $\mathrm{Tc}_{50}$.

Table 13: $\mathrm{Td}_{50}$ values of 5-methylfurfural concentrations and folds relative to $\mathrm{Tc}_{50}$.

\begin{tabular}{|c|c|c|}
\hline \multirow{2}{*}{ Control } & Tc50 (minutes) & \multirow{2}{*}{ Fold } \\
\cline { 2 - 2 } & $\mathbf{2 \pm 0 . 9}$ & \\
\hline 5-methylfurfural concentrations (mM) & Td50 (minutes) & \\
\hline 25 & $2.6 \pm 1.2$ & 1.3 \\
\hline 50 & $3 \pm 1.07$ & 1.5 \\
\hline 75 & $3 \pm 0.80$ & 1.5 \\
\hline
\end{tabular}

\section{SAR and Comparative Activities of Aldehyde-Containing} Aromatic Compounds

The anti-polymerization activities test aromatic aldehydes related to vanillin and 5 -HMF are summarized in Table 14 (Structure 14). Delay times are represented by the average \pm SD, $\mathrm{n}=4{ }^{*}$ statistically different from control at $p<0.001$. The results shown in Table 14 clearly indicate that vanillin is the most effective anti-polymerization activity though at $50 \mathrm{mM}$ concentration. The delay time of 31 minutes is huge and may permit the passage of red blood cell in the capillary before $\mathrm{HbS}$ polymerizes. Second to vanillin is the $5-\mathrm{HMF}$ with delay time of 16 minutes at $75 \mathrm{mM}$ concentration. Following, the two leading compounds; comes 3 -furfural with delay time of 9 minutes at $75 \mathrm{mM}$ concentration. The 2,4-dihydroxy benzaldehyde 5-methyl furfural showed no activities at the highest soluble concentrations.<smiles>[R2]c1cc(C=O)cc([R])c1[R]</smiles>

$$
\begin{array}{llc} 
& \text { 3. furfural } & \text { 4. } \\
\text { 1. vanillin } & \text { 4-methylfurfural } & \text { O } \\
\text { 2. 2,4-dihydroxybenzaldehyde } & 5.5 \text {-hydroxymethylfurfural } & \text { 6. 3-furfural }
\end{array}
$$
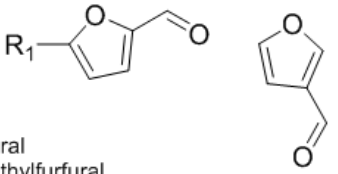

Structure 14: Aldehyde-Containing Aromatic Compounds.

Table 14: Comparative activities of aldehyde-containingaromatic compounds

\begin{tabular}{|c|c|c|c|c|c|}
\hline Compound & $\begin{array}{c}\text { Concentration } \\
\text { (mM) }\end{array}$ & $\mathbf{R}_{\mathbf{1}}$ & $\mathbf{R}_{\mathbf{2}}$ & $\mathbf{R}_{\mathbf{3}}$ & $\begin{array}{c}\mathbf{T d}_{\mathbf{5 0}} \\
\left(\mathbf{m i n u t e s}^{\mathbf{m} \mathbf{S D})}\right.\end{array}$ \\
\hline 1 & 50 & $\mathrm{CH}_{3}-\mathrm{O}$ & $\mathrm{OH}$ & $\mathrm{H}$ & $31 \pm 0.1$ \\
\hline 2 & 7.5 & $\mathrm{OH}$ & $\mathrm{H}$ & $\mathrm{OH}$ & inactive \\
\hline 3 & 75 & $\mathrm{H}$ & & & $4^{*} \pm 1$ \\
\hline 4 & 75 & $\mathrm{CH}_{3}$ & $\mathrm{H}$ & $\mathrm{H}$ & Inactive \\
\hline 5 & 75 & $\mathrm{OH}_{-}-\mathrm{CH}_{3}$ & $\mathrm{H}$ & $\mathrm{H}$ & $16^{*} \pm 2$ \\
\hline 6 & 75 & $\mathrm{H}$ & $\mathrm{HH}$ & $\mathrm{H}$ & $9^{*} \pm 0.43$ \\
\hline
\end{tabular}

SAR and Comparative Activities of Vanillin-Related Aromatic Carboxylic Acids

Table 15 summarizes the comparative activities of carboxylic acids related to vanillin structure. It is clear that oxidizing the 
aldehyde group of vanillin into vanillic acid, compound 1, (Table 15). Resulted in a total loss of activity. It appears that benzoic acids are not good parent nucleus for activity. This is also confirmed by the loss of activity of the isomer; compound 2. Interestingly, homovanillic acid, a homolog of vanillic acid, compound 4, Table 15, showed a delay time of 13 minutes at $75 \mathrm{mM}$ concentration. More interesting, that the $\alpha$-hydroxy derivative of phenyl acetic acid (mandelic acid) , compound 3, showed more 20 minutes delay time at $100 \mathrm{mM}$ concentration, even higher than substituted mandelic acid with vanillin like methoxy and hydroxyl groups, compound 5 (Structure 15).

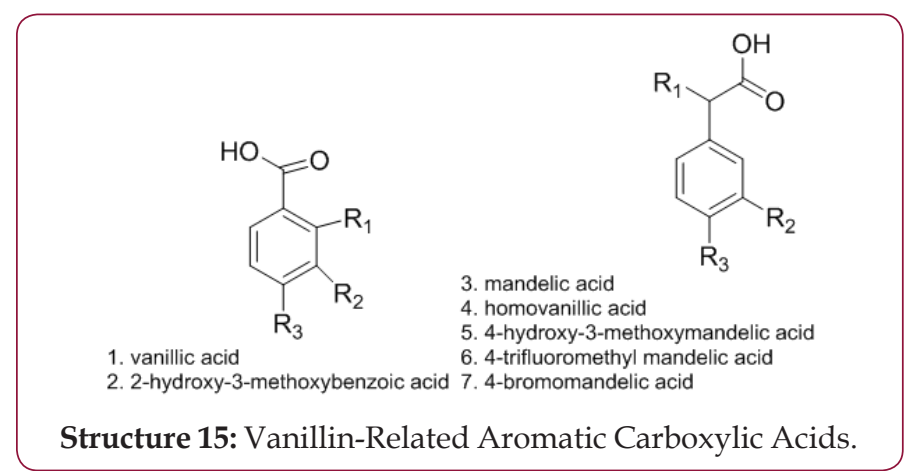

Table 15: Comparative Activities of Vanillin-related aromatic carboxylic acids.

\begin{tabular}{|c|c|c|c|c|c|}
\hline Compound & $\begin{array}{c}\text { Concentration } \\
(\mathbf{m M})\end{array}$ & $\mathbf{R}_{\mathbf{1}}$ & $\mathbf{R}_{\mathbf{2}}$ & $\mathbf{R}_{\mathbf{3}}$ & $\begin{array}{c}\mathbf{T d}_{\mathbf{5 0}} \\
\text { (minutes) }\end{array}$ \\
\hline Control & 0 & - & - & - & $3 \pm 0.1$ \\
\hline 1 & 12.5 & $\mathrm{H}$ & $\mathrm{CH}_{3} \mathrm{O}$ & $\mathrm{H}$ & $2 \pm 0.7$ \\
\hline 2 & 12.5 & $\mathrm{OH}$ & $\mathrm{CH}_{3} \mathrm{O}$ & $\mathrm{H}$ & $2 \pm 0.7$ \\
\hline 3 & 100 & $\mathrm{OH}$ & $\mathrm{H}$ & $\mathrm{H}$ & $>20$ \\
\hline 4 & 75 & $\mathrm{H}$ & $\mathrm{CH}_{3} \mathrm{O}$ & $\mathrm{OH}$ & $13^{* *} \pm 5$ \\
\hline 5 & 100 & $\mathrm{OH}$ & $\mathrm{CH}_{3} \mathrm{O}$ & $\mathrm{OH}$ & $11^{*} \pm 1$ \\
\hline 6 & 25 & $\mathrm{OH}$ & $\mathrm{H}$ & $\mathrm{CF}_{3}$ & $5^{*} \pm 0.5$ \\
\hline 7 & 25 & $\mathrm{OH}$ & $\mathrm{H}$ & $\mathrm{Br}$ & $5^{*} \pm 1$ \\
\hline
\end{tabular}

This work is licensed under Creative Commons Attribution 4.0 License

Submission Link: https://biomedres.us/submit-manuscript.php

\section{Conclusion}

In conclusion, in the current study revealed the antipolymerization activities of several compounds related to vanillin and 5-HMF structures. The high activities of the newly studied compounds, such as 4-hydroxy-3-methoxymandelic acid, homovanillic acid and 3-furfural provide a new set of compounds that can be subjected to further investigation as potential agents to help treat the sickle cell disease.

\section{Acknowledgment}

The authors would like to thank MCPHS University for financially supporting this research.

\section{References}

1. Mehanna A (2001) Sickle cell anemia and antisickling agents then and now. Curr Med Chem 8(2): 79-88.

2. Mehanna A (2017) High Throughput Kinetic Assay for Screening Potential Inhibitors of Sickle Hemoglobin Polymerization. Med Chem 7(7): 193-196.

3. Mehanna A, Hendawy, M (2017) The Effect of Thiol Containing Compounds on the Kinetics of Sickle Hemoglobin. JJMedChem 2(1): $1-13$.

4. Abraham D, Mehanna A, Wireko F, Whitney J, Thomas R, et al. (1991) Vanillin, a potential agent for the treatment of sickle cell anemia. Blood 77(6): 1334-1341.

5. Thesis A, Asakura T, Love W, Basic R, Sciences M, et al. (2004) 5-Hydroxymethyl-2-Furfural Modifies Intracellular Sickle Hemoglobin and Inhibits Sickling of Red Blood Cells. Br J Haematol 87(6): 368-375.

6. Abdulmalik O, Safo M, Chen Q, Yang Brugnara J, Ohene Frempong, et al. (2005) 5-Hydroxymethyl-2-Furfural Modifies Intracellular Sickle Haemoglobin and Inhibits Sickling of Red Blood Cells. Br J Haematol 128(4): 552-561.

7. Safo M, Abdulmalik, Danso Danquah O, Burnett J, Nokuri S (2004) Structural Basis for the Potent Antisickling Effect of a Novel Class of Five-Membered Heterocyclic Aldehydic Compounds. J Med Chem (47): 4665-4676.

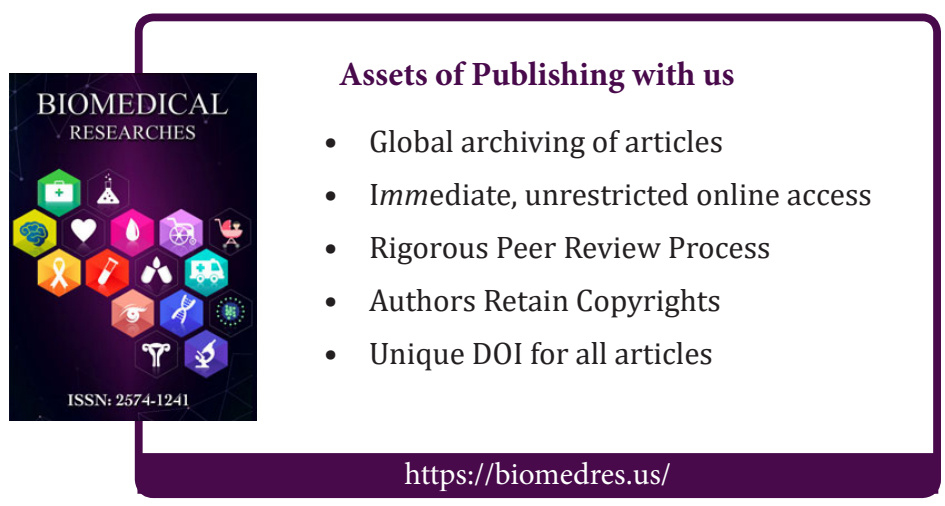

